Central European Journal of Energetic Materials, 2016, 13(2), 289-300

ISSN 1733-7178

e-ISSN 2353-1843

\title{
A New Energetic Binder: Glycidyl Nitramine Polymer
}

\author{
Franziska M. BETZLER, Vera A. HARTDEGEN, \\ Thomas M. KLAPÖTKE*, Stefan M. SPROLL \\ Department Chemistry, Energetic Materials Research, \\ Ludwig-Maximilian University of Munich, \\ Butenandtstr. 5-13, D-81377 Munich, Germany \\ "E-mail:tmk@cup.uni-muenchen.de
}

\begin{abstract}
A new energetic glycidyl-based polymer containing nitramine groups (glycidyl nitramine polymer, GNAP) was synthesized using glycidyl azide polymer (GAP) as the starting material. The synthesis involved STAUDINGER azide-amine conversion, followed by carbamate protection of the amino group, nitration with nitric acid (100\%) and trifluoroacetic anhydride and was concluded by deprotection with aqueous ammonia.

The products obtained were characterized by elemental analysis and vibrational spectroscopy (IR). The energetic properties of GNAP were determined using bomb calorimetric measurements and calculated with the EXPLO5 V6.02 computer code, showing better values regarding the energy of explosion $\left(\Delta_{\mathrm{E}} U=-4813 \mathrm{~kJ} \mathrm{~kg}^{-1}\right)$, the detonation velocity $\left(V_{\text {Det }}=7165 \mathrm{~m} \cdot \mathrm{s}^{-1}\right)$, as well as the detonation pressure $\left(p_{\mathrm{CJ}}=176 \mathrm{kbar}\right)$, than the comparable polymers GAP and polyGLYN. The explosion properties were tested by impact sensitivity (IS), friction sensitivity (FS), differential scanning calorimetry (DSC), thermogravimetric analysis (TGA) and electrostatic discharge (ESD) equipment. The results revealed GNAP to be insensitive towards friction and electrostatic discharge, less sensitive towards impact $(40 \mathrm{~J})$ and a decomposition temperature $\left(170^{\circ} \mathrm{C}\right)$ in the range of polyGLYN.
\end{abstract}

Keywords: energetic polymer, glycidyl nitramine, GNAP, GAP, polyGLYN

\section{Introduction}

Polymers play an important role in modern energetic formulations of any kind. They are mostly used as binders to reduce the sensitivity of energetic materials 
towards heat, impact and friction as well as to improve the mechanical resistance by constructing a protective matrix around the mainly solid energetic ingredients [1].

The use of inert polymers, such as hydroxyl-terminated polybutadiene (HTPB) or terpolymers based on butadiene, acrylonitrile and acrylic acid (PBAN) has been widely reported [2]. Although these polymers are well suited as binders due to their properties, they have a major issue of being non-energetic. The use of such binders in energetic formulations leads to a loss of the energetic performance of the overall system. Therefore the development of energetic polymers has gained more and more interest in the recent decades $[1,3]$.

Two examples of energetic polymers, which are already commercially available are the glycidyl azide polymer (GAP) and poly(glycidyl nitrate) (polyGLYN) (Figure 1).

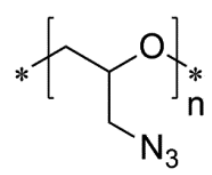

GAP

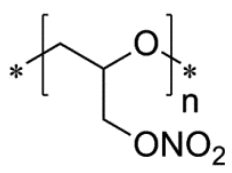

polyGLYN

Figure 1. Structures of GAP and polyGLYN.

Due to their liquid consistency, both of these compounds need to be cured if used as binders in energetic formulations. This is achieved by adding a curing agent to the binder containing the explosive composition. Usually di-isocyanato compounds are used to cure the hydroxyl-terminated glycidyl polymers, forming a urethane linkage. The reaction of GAP with the curing agent diphenylmethane4,4'-diisocyanate (MDI) is shown in Scheme 1 as an example [4].

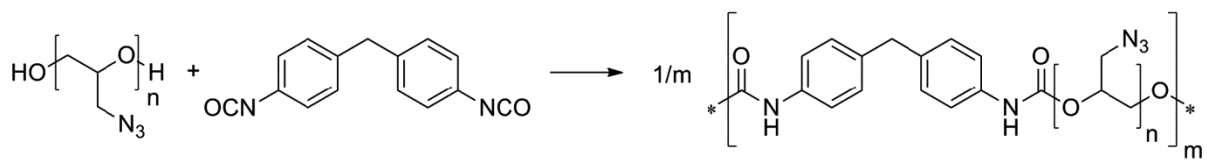

Scheme 1. Curing of hydroxyl-terminated GAP using MDI.

This curing step of the glycidyl polymer has the disadvantage of reducing the final energy output of the formulation as the isocyanates used are non-energetic. Furthermore, the curing of these polymers is often accompanied by gas evolution leading to void formation in the composition. Consequently the objective of the present work was to synthesize a solid glycidyl-based energetic polymer for binder applications. 


\section{Experimental}

GAP was obtained from BAYERN-CHEMIE mbH. All other chemical reagents and solvents of analytical grade were obtained from Sigma-Aldrich, Acros Organics or $\mathrm{ABCR}$ and used without further purification.

Infrared spectra were measured with a Perkin-Elmer Spectrum BXFTIR spectrometer equipped with a SMITHS DuraSAmPLIR II ATR device. All spectra were recorded at ambient temperature. Elemental analyses $(\mathrm{C} / \mathrm{H} / \mathrm{N})$ were performed with an Elementar Vario EL or Vario Micro Analyzer. Melting points were determined in capillaries with a Büchi Melting PoinT B-540 instrument. Decomposition temperatures were determined by differential scanning calorimetry (DSC) with a LINSEIS DSC PT10 calibrated with standard pure indium and zinc, using a heating rate of $5{ }^{\circ} \mathrm{C} \cdot \mathrm{min}^{-1}$ in covered $\mathrm{Al}$-containers with a hole in the lid and a nitrogen flow of $20 \mathrm{~mL} \cdot \mathrm{min}^{-1}$. Thermogravimetric analysis (TGA) was performed in an argon atmosphere on a SETARAM 92-2400 TG-DTA 1600 , using a heating rate of $5{ }^{\circ} \mathrm{C} \cdot \mathrm{min}^{-1}$ in a corundum crucible $(80 \mu \mathrm{L})$. Bomb Calorimetry was undertaken using a PARR 1356 IsOPERIBOL Bomb CAlorimeter with a PARr 1108CL Oxygen Bomb. For the analysis three samples of 100-150 mg of the energetic substance were mixed with $950-1100 \mathrm{mg}$ of benzoic acid. The mixture was converted into a pellet which was then used for the measurement. Pycnometric measurements were carried out with a QUANTACHROME ULTRAPYC 1200 e pycnometer. Impact and friction sensitivity tests were carried out according to STANAG 4489 [5] and STANAG 4487 [6] modified instructions [7] using a BAM (Bundesanstalt für Materialforschung) drop hammer and friction tester [8]. The classification of the tested compounds are based on the "UN Recommendations on the Transport of Dangerous Goods". Electrostatic sensitivities were measured with a OZM small scale electrostatic discharge tester [9].

CAUTION! All nitramine containing compounds are potentially explosive energetic materials. Although no hazards were observed during the preparation and handling of these compounds, nevertheless, their synthesis and handling requires additional meticulous safety precautions (grounded equipment, Kevlar ${ }^{\circledR}$ gloves, Kevlar ${ }^{\circledR}$ sleeves, face shield, leather coat, and ear plugs).

\subsection{Synthesis of glycidyl amino hydrochloride polymer (1)}

GAP (5.01 g, $50.56 \mathrm{mmol}, \mathrm{M}_{\mathrm{n}} \sim 2000 \mathrm{~g} \cdot \mathrm{mol}^{-1}$, OH-terminated) was dissolved in THF (20 mL) and 2 equivalents of $\mathrm{PPh}_{3}(26.52 \mathrm{~g}, 101.12 \mathrm{mmol})$ dissolved in THF $(150 \mathrm{~mL})$, were added slowly. After stirring for $24 \mathrm{~h}$ at $60^{\circ} \mathrm{C}$, the mixture 
was poured into water $(200 \mathrm{~mL})$ and stirred for a further $24 \mathrm{~h}$ at $\mathrm{rt}$. The colorless precipitate was filtered off, the remaining solution was acidified with conc. $\mathrm{HCl}$ and then washed with dichloromethane $(5 \times 50 \mathrm{~mL})$. The aqueous phase was then evaporated. After drying in vacuo, $5.43 \mathrm{~g}$ (49.55 mmol, 98\%) of 1 were obtained as a colorless powder.

Melting point: $90^{\circ} \mathrm{C}$; IR (ATR, $\left.\mathrm{cm}^{-1}\right)$ : $=3380(\mathrm{w}), 2876(\mathrm{~s}), 2362(\mathrm{~m})$, 2339 (w), 1991 (vw), 1738 (w), 1593 (m), 1593 (w), 1489 (s), 1458 (m), $1421(\mathrm{w}), 1350(\mathrm{w}), 1328(\mathrm{w}), 1091(\mathrm{vs}), 1011(\mathrm{~s}), 938(\mathrm{~m}), 914(\mathrm{~m}), 843(\mathrm{w})$; EA $\left(\mathrm{C}_{3} \mathrm{H}_{8} \mathrm{ClNO} * 0.5 \mathrm{H}_{2} \mathrm{O} ; \mathrm{M}=118.56 \mathrm{~g} \cdot \mathrm{mol}^{-1}\right)$ calc $(\%)$ : C 30.39, H 7.65, N 11.81, Cl 29.90; found: C 30.03, H 7.44, N 11.65, Cl 31.17.

\subsection{Synthesis of glycidyl ethyl carbamate polymer (2)}

Compound 1 ( $5.83 \mathrm{~g}, 53.20 \mathrm{mmol})$ was dissolved in $2 \mathrm{M} \mathrm{NaOH}(80 \mathrm{~mL}, 160 \mathrm{mmol})$ and cooled down to $0{ }^{\circ} \mathrm{C}$. Ethyl chloroformate $(6.93 \mathrm{~g}, 63.85 \mathrm{mmol})$ was then added dropwise. The solution was stirred for $30 \mathrm{~min}$ at $0{ }^{\circ} \mathrm{C}$. The solvent was decanted, the viscous orange residue was dissolved in dichloromethane $(50 \mathrm{~mL})$ and then washed with brine $(2 \times 30 \mathrm{~mL})$ followed by water $(1 \times 30 \mathrm{~mL})$. The organic phase was dried over $\mathrm{MgSO}_{4}$ and evaporated. After drying under reduced pressure, $4.13 \mathrm{~g}(28.50 \mathrm{mmol}, 54 \%)$ of 2 was obtained as an orange viscous liquid.

IR $\left(\right.$ ATR, $\left.\mathrm{cm}^{-1}\right):=3329(\mathrm{~m}), 2980(\mathrm{w}), 2934(\mathrm{w}), 2875(\mathrm{w}), 1690(\mathrm{vs})$, $1525(\mathrm{~s}), 1480(\mathrm{~m}), 1445(\mathrm{~m}), 1378(\mathrm{w}), 1335(\mathrm{w}), 1245(\mathrm{vs}), 1170(\mathrm{~m}), 1093(\mathrm{~s})$, $1029(\mathrm{~s}), 778(\mathrm{~m}) . \mathbf{E A}\left(\mathrm{C}_{6} \mathrm{H}_{11} \mathrm{NO}_{3} ; \mathrm{M}=145.16 \mathrm{~g} \cdot \mathrm{mol}^{-1}\right)$ calc $(\%): \mathrm{C} 49.65, \mathrm{H}$ 7.64, N 9.65; found: C 48.69, H 7.56, N 9.34.

\subsection{Synthesis of glycidyl ethyl $\mathbf{N}$-nitrocarbamate polymer (3)}

Trifluoroacetic anhydride $(83.69 \mathrm{~g}, 393.7 \mathrm{mmol})$ was cooled down to $0{ }^{\circ} \mathrm{C}$. Conc. nitric acid (29.77 g, $472.44 \mathrm{mmol})$ was added dropwise and the mixture was stirred for $10 \mathrm{~min}$. Subsequently, the nitration mixture was added to precooled $\mathbf{2}$ ( $3.81 \mathrm{~g}, 26.25 \mathrm{mmol})$ and stirred for $1 \mathrm{~h}$ at $0{ }^{\circ} \mathrm{C}$. The solution was poured into ice water and stirred over night. The solvent was decanted, the yellowish residue was dissolved in dichloromethane $(50 \mathrm{~mL})$ and then washed with brine $(2 \times 20 \mathrm{~mL})$ and water $(1 \times 20 \mathrm{~mL})$. The combined aqueous phases were extracted once with dichloromethane. After drying the combined organic phases over $\mathrm{MgSO}_{4}$, the solvent was evaporated and $\mathbf{3}$ was dried under reduced pressure to give $4.16 \mathrm{~g}$ (21.90 mmol, 83\%) of a yellowish, rubber-like solid.

IR $\left(\right.$ ATR, $\left.\mathrm{cm}^{-1}\right)$ : = $2986(\mathrm{w}), 2914(\mathrm{vw}), 2878(\mathrm{vw}), 1765(\mathrm{~s}), 1643(\mathrm{w})$, $1568(\mathrm{~s}), 1433$ (w), 1371 (w), $1288(\mathrm{~m}), 1235$ (m), 1204 (s), 1174 (vs), 1150 (vs), 986 (s), 873 (s), 750 (s), 679 (w); EA $\left(\mathrm{C}_{6} \mathrm{H}_{10} \mathrm{~N}_{2} \mathrm{O}_{5} ; \mathrm{M}=190.15 \mathrm{~g} \cdot \mathrm{mol}^{-1}\right)$ calc (\%): C 37.90, H 5.30, N 14.73; found: C 37.01, H 5.22, N 14.58. 


\subsection{Synthesis of glycidyl nitramine polymer (GNAP, 4)}

Compound 3 (3.97 g, $20.87 \mathrm{mmol}$ ) was added to conc. aqueous ammonia $(125 \mathrm{~mL})$, and the mixture was stirred for $2 \mathrm{~h}$ at $45^{\circ} \mathrm{C}$ until a clear solution was obtained. After acidifying with conc. $\mathrm{HCl}$ the solution was stirred over night at room temperature. The solvent was decanted and the residue was washed with boiling water $(100 \mathrm{~mL})$. The water was decanted and $\mathbf{4}$ was dried in vacuo to yield $64 \%$ (1.58 g, $13.38 \mathrm{mmol})$ of a sticky, yellow powder.

Density: $\boldsymbol{\rho}=1.5 \mathrm{~g} \cdot \mathrm{cm}^{-3} ;$ DSC $\left(5^{\circ} \mathrm{C} \cdot \mathrm{min}^{-1}\right): \mathrm{T}_{\text {Dec }}: 170{ }^{\circ} \mathrm{C}$; IR $\left(\mathrm{ATR}, \mathrm{cm}^{-1}\right)$ : $=3505(\mathrm{vw}), 3267(\mathrm{~m}), 3128(\mathrm{w}), 2930(\mathrm{w}), 2885(\mathrm{w}), 1718(\mathrm{vw}), 1566(\mathrm{~s})$, 1440 (m), 1384 (s), 1304 (vs), 1093 (vs), 1073 (vs), 858 (vw), 770 (w), 740 (w); EA $\left(\mathrm{C}_{3} \mathrm{H}_{6} \mathrm{~N}_{2} \mathrm{O}_{3} * 0.06 \mathrm{C}_{3} \mathrm{H}_{5} \mathrm{O}_{2} ; \mathrm{M}=122.48 \mathrm{~g} \cdot \mathrm{mol}^{-1}\right)$ calc (\%): C 31.19, H 5.18, N 22.87; found: C 31.21, H 5.14, N 22.76. Sensitivities: IS: 40 J; FS: > 360 N; ESD: $1.5 \mathrm{~J}$.

\section{Results and Discussion}

\subsection{Synthesis}

It was necessary to convert the azide moieties of GAP into amino groups by applying the STAUDINGER reaction [10], before proceeding to the desired nitramine. To avoid multiple nitration, the amino groups of $\mathbf{1}$ were protected using ethyl chloroformate. After nitration, the deprotection of $\mathbf{3}$ was performed with aqueous ammonia. The desired compound $\mathbf{4}$ was obtained as a sticky, yellow powder. Due to the solid character of GNAP, no or at least less curing agents should be needed if used in energetic formulations. The synthetic route to obtain GNAP is shown in Scheme 2.
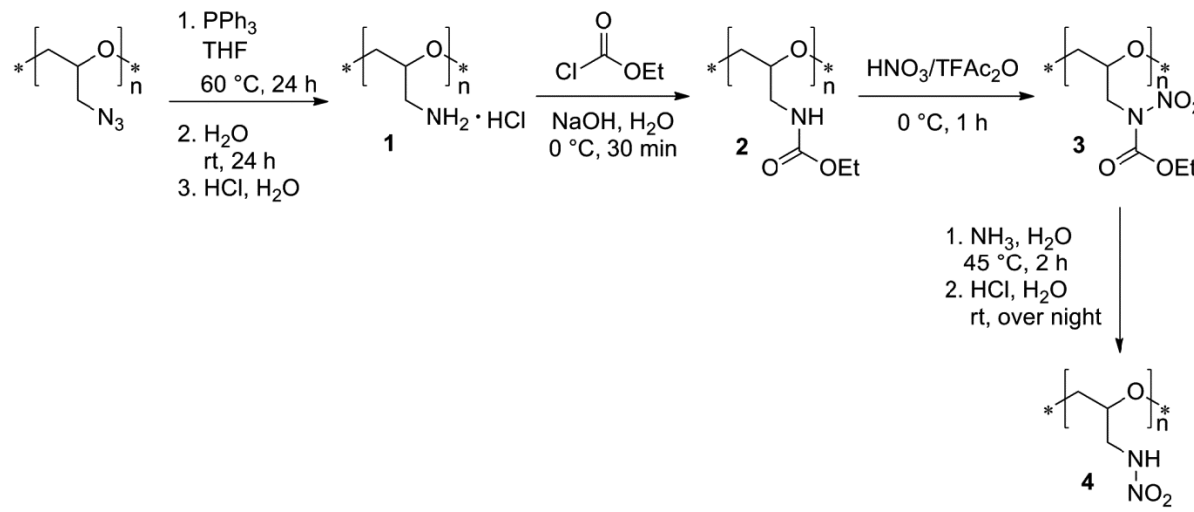

Scheme 2. Synthetic route towards glycidyl nitramine polymer (GNAP). 


\subsection{Spectroscopic and elemental analysis}

The compounds obtained were characterized using IR spectroscopy and elemental analysis. The measured IR spectra of GAP and all of the synthesized compounds are shown in Figure 2.
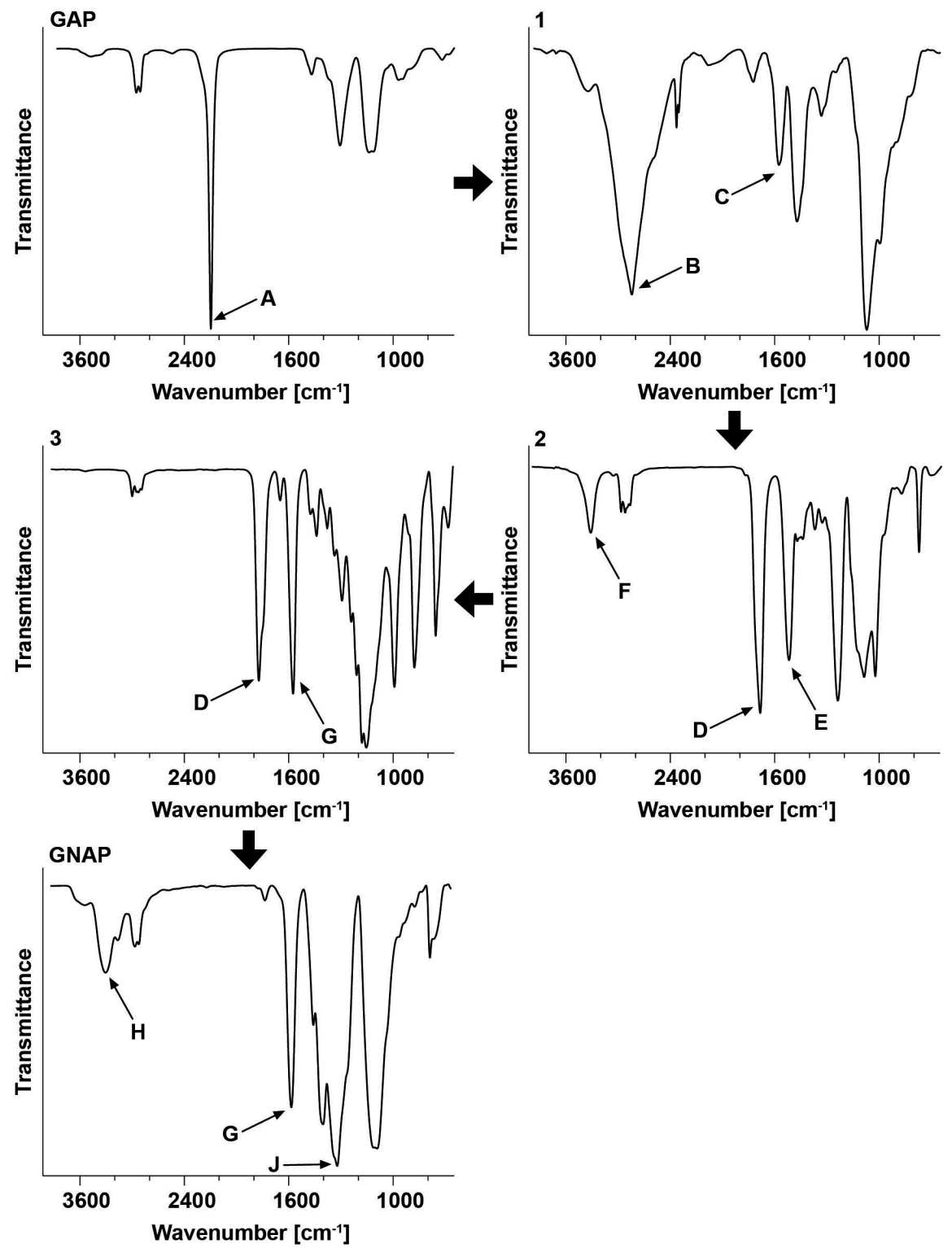

Figure 2. Measured IR spectra of GAP, compounds 1-3 and GNAP. 
After the STAUDINGER azide-amine conversion, the measured elemental analysis of 1 fitted well with the calculated values for one hydrochloride molecule and 0.5 molecules of water per repeating unit of the amino polymer. A comparison of the IR spectra of GAP and 1 revealed significant differences. The characteristic strong vibration of the azide group of GAP at about $2100 \mathrm{~cm}^{-1}$ (A) [11] was completely absent in the spectrum of the amino hydrochloride $\mathbf{1}$. Instead, the valence and bending vibrations of the ammonium group appeared at $3380 \mathrm{~cm}^{-1}(\mathrm{~B})$ and $1600 \mathrm{~cm}^{-1}(\mathrm{C})$, respectively $[11,12]$.

Elemental analysis and the measured IR spectra of the carbamate protected amino polymer $\mathbf{2}$, as well as of the nitrated carbamate compound $\mathbf{3}$, proved the formation of both of the desired products. The IR spectrum of $\mathbf{2}$ showed the two characteristic carbamate vibrations, the $\mathrm{C}=\mathrm{O}$ stretching at $1700 \mathrm{~cm}^{-1}$ (D) and the $\mathrm{N}-\mathrm{H}$ bending vibration (Amide II vibration) at $1520 \mathrm{~cm}^{-1}$ (E) with strong intensities. In the vibrational spectrum of $\mathbf{3}$, the signals at $3300 \mathrm{~cm}^{-1}(\mathrm{~F})$ and $1520 \mathrm{~cm}^{-1}$ (E) had vanished due to the nitration of the protected $\mathrm{N}-\mathrm{H}$ group. Instead, a strong signal at about $1600 \mathrm{~cm}^{-1}(\mathrm{G})$ appeared, which can be assigned to the asymmetric vibration of the nitramino group [11]. In addition, the vibration of the carbamate $\mathrm{C}=\mathrm{O}$ group $(\mathrm{D})$ had moved to higher wavenumbers $\left(1770 \mathrm{~cm}^{-1}\right)$.

After the deprotection of $\mathbf{3}$ and following acidification, the elemental analysis of the obtained compound (4) revealed some remaining carbamate protecting groups in the polymer ( 1 out of 18 repeating units).

The measured IR spectrum of GNAP showed a lack of the carbamate vibrations and a reappearance of the $\mathrm{N}-\mathrm{H}$ stretching band at about $3270 \mathrm{~cm}^{-1}$ $(\mathrm{H})$ for the primary nitramine [11]. Furthermore the two existing asymmetric and symmetric vibrations $\left(1600 \mathrm{~cm}^{-1}\right.$ and $\left.1300 \mathrm{~cm}^{-1}\right)$ of the nitramine group were visible $(\mathrm{G}, \mathrm{J})[11]$. This proves the successful synthesis of the glycidyl nitramine polymer (GNAP, 4).

\subsection{Thermodynamic and energetic properties}

Differential scanning calorimetric measurements to determine the decomposition temperatures $\left(T_{\text {Dec. }}\right)$ of GNAP were performed in closed Al-containers, containing a hole $(0.1 \mathrm{~mm})$ for gas release. GNAP shows a decomposition point at $170{ }^{\circ} \mathrm{C}$ (onset of decomposition) (Figure 3). This value is below the decomposition point of GAP $\left(216{ }^{\circ} \mathrm{C}\right)$ [13] and in the range of that of polyGLYN $\left(170{ }^{\circ} \mathrm{C}\right)$ [14]. In addition, a TGA was recorded in the temperature range $20-400{ }^{\circ} \mathrm{C}$ at a heating rate of $5{ }^{\circ} \mathrm{C} \cdot \mathrm{min}^{-1}$ in an argon atmosphere (Figure 4). GNAP showed a weight loss commencing around $170{ }^{\circ} \mathrm{C}$, which can be explained by the start decomposition of the side chain, beginning with the nitramine groups. A second step around $220^{\circ} \mathrm{C}$ is assignable to the decomposition of the polymeric backbone. 
On reaching the end temperature of $400{ }^{\circ} \mathrm{C}$, an overall (incompleted) weight loss of $76.7 \%$ was recorded.

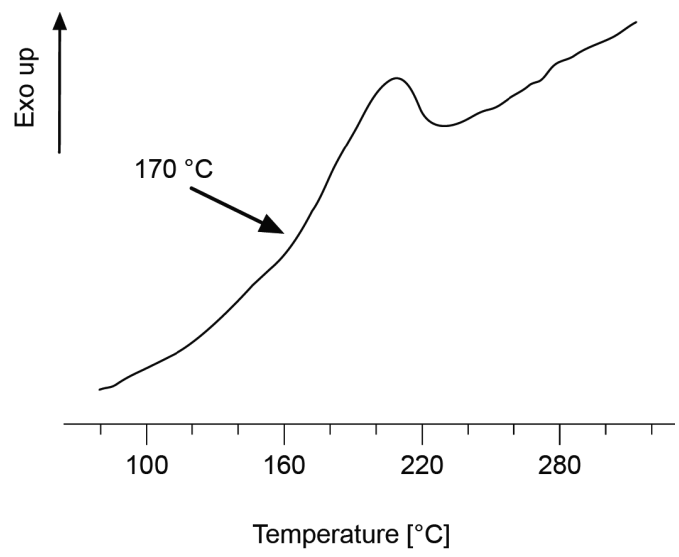

Figure 3. DSC plot of GNAP (onset temperature).

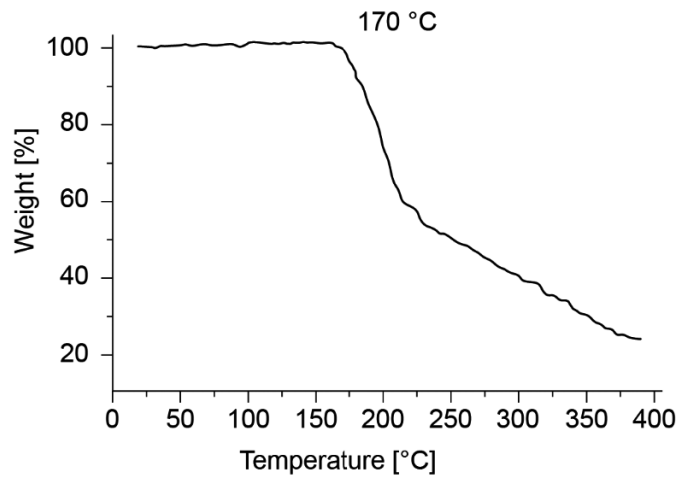

Figure 4. TGA plot of GNAP.

The sensitivity data were obtained using a BAM drop hammer and friction tester [9]. These methods revealed that GNAP is insensitive towards friction $(>360 \mathrm{~N}$ ) and less sensitive towards impact (40 J), compared to GAP(IS: $8 \mathrm{~J}, \mathrm{FS}$ : $>360 \mathrm{~N}$ ) [13] and polyGLYN (IS: $10 \mathrm{~J}$, FS: $112 \mathrm{~N}$ ), GNAP shows higher stability towards impact $(40 \mathrm{~J})$ and equal or better stability towards friction $(>360 \mathrm{~N})$, which can be regarded as an advantage in terms of safety.

For analyzing the energetic properties of GNAP, the energy of combustion $\left(\Delta U_{\mathrm{c}}\right)$ was determined via bomb calorimetry. The enthalpy of formation could be calculated from the value obtained by applying the Hess thermochemical cycle, as reported in the literature [15]. The required heats of formation of $\mathrm{H}_{2} \mathrm{O}(1)$ and 
$\mathrm{CO}_{2}(\mathrm{~g})$ of $-286 \mathrm{~kJ} \cdot \mathrm{mol}^{-1}$ and $-394 \mathrm{~kJ} \cdot \mathrm{mol}^{-1}$ respectively, were obtained from the literature [16]. The combustion reaction of GNAP is given in Scheme 3.

$$
\mathrm{C}_{3} \mathrm{H}_{6} \mathrm{~N}_{2} \mathrm{O}_{3}+3 \mathrm{O}_{2} \rightarrow 3 \mathrm{CO}_{2}(\mathrm{~g})+3 \mathrm{H}_{2} \mathrm{O}(\mathrm{l})+\mathrm{N}_{2}(\mathrm{~g})
$$

Scheme 3. Combustion reaction of GNAP (repeating unit).

All calculations concerning the detonation parameters were carried out using the program package EXPLO5 (version 6.02) [17] and were based on the calculated heats of formation and attributed to the corresponding densities. The data obtained for GNAP is given in Table 1 and compared to the energetic values of GAP and polyGLYN.

Table 1. Energetic data of GNAP compared to GAP and polyGLYN

\begin{tabular}{|l|c|c|c|}
\hline & GNAP & GAP & polyGLYN \\
\hline Formula (repeating unit) & $\mathrm{C}_{3} \mathrm{H}_{6} \mathrm{~N}_{2} \mathrm{O}_{3}$ & $\mathrm{C}_{3} \mathrm{H}_{5} \mathrm{~N}_{3} \mathrm{O}$ & $\mathrm{C}_{3} \mathrm{H}_{5} \mathrm{NO}_{4}$ \\
\hline Molecular mass $\left[\mathrm{g} \cdot \mathrm{mol}^{-1}\right]$ & 118.09 & 99.09 & 119.08 \\
\hline Impact sensitivity $[\mathrm{J}]^{\mathrm{a}}$ & 40 & 8 & $10^{\mathrm{r}}$ \\
\hline Friction sensitivity $[\mathrm{N}]^{\mathrm{b}}$ & $>360$ & $>360$ & $112^{\mathrm{r}}$ \\
\hline$\Omega[\%]^{\mathrm{c}}$ & -81 & -121 & -60 \\
\hline$T_{\text {Dec }}\left[{ }^{\circ} \mathrm{C}\right]^{\mathrm{d}}$ & 170 & 216 & 170 \\
\hline$\rho\left[\mathrm{g} \cdot \mathrm{cm}^{-3}\right]^{\mathrm{e}}$ & 1.5 & 1.3 & 1.4 \\
\hline$-\Delta U_{\text {comb }}\left[\mathrm{cal} \cdot \mathrm{g}^{-1}\right]^{\mathrm{f}}$ & 3831 & - & - \\
\hline$-\Delta H_{\mathrm{comb}}\left[\mathrm{kJ} \cdot \mathrm{mol}^{-1}\right]^{\mathrm{g}}$ & 1896 & - & - \\
\hline$\Delta_{\mathrm{f}} H_{\mathrm{m}}{ }^{\circ}\left[\mathrm{kJ} \cdot \mathrm{mol}^{-1}\right]^{\mathrm{h}}$ & -146 & 142 & -323 \\
\hline$\Delta_{\mathrm{f}} U^{\circ}\left[\mathrm{kJ} \cdot \mathrm{kg}^{-1}\right]^{\mathrm{i}}$ & -1261 & 1545 & -2609 \\
\hline EXPLO 5 V6.02 values & \multicolumn{5}{|l|}{} \\
\hline$-\Delta_{\mathrm{E}} U^{\circ}\left[\mathrm{kJ} \cdot \mathrm{kg}^{-1}\right]^{\mathrm{j}}$ & 4813 & 4307 & 4433 \\
\hline$T_{\mathrm{E}}\left[{ }^{\circ} \mathrm{C}\right]^{\mathrm{k}}$ & 2701 & 2404 & 2746 \\
\hline$p_{\mathrm{CJ}}[\mathrm{kbar}]^{1}$ & 176 & 129 & 144 \\
\hline$V_{\text {Det }}\left[\mathrm{m} \cdot \mathrm{s}^{-1}\right]^{\mathrm{m}}$ & 7165 & 6638 & 6476 \\
\hline $\mathrm{Gas} \mathrm{vol} \cdot\left[\mathrm{L} \cdot \mathrm{kg}^{-1}\right]^{\mathrm{n}}$ & 844 & 822 & 808 \\
\hline$I_{\mathrm{s}}[\mathrm{s}]^{\circ}$ & 209 & 207 & 205 \\
\hline
\end{tabular}

${ }^{\mathrm{a}}$ BAM drop hammer (1 of 6, RDX: $\left.7 \mathrm{~J}\right)$; ${ }^{\mathrm{b}} \mathrm{BAM}$ friction tester $(1$ of 6 , RDX: $120 \mathrm{~N})$; ${ }^{\mathrm{c}}$ oxygen balance; ${ }^{\mathrm{d}}$ temperature of decomposition by $\operatorname{DSC}\left(\beta=5{ }^{\circ} \mathrm{C}\right.$, onset values $)$; ${ }^{\mathrm{e}}$ density derived from pycnometer measurement; ${ }^{\mathrm{f}}$ experimental combustion energy (constant volume); ${ }^{\mathrm{g}}$ experimental molar enthalpy of combustion; ${ }^{\mathrm{h}}$ molar enthalpy of formation; ${ }^{\mathrm{i}}$ energy of formation; ${ }^{\mathrm{j}}$ energy of explosion; ${ }^{\mathrm{k}}$ explosion temperature; ${ }^{1}$ detonation pressure; ${ }^{\mathrm{m}}$ detonation velocity; ${ }^{\mathrm{n}}$ assuming only gaseous products; ${ }^{\circ}$ specific impulse (isobaric combustion, chamber pressure 70 bar, frozen expansion); ${ }^{\mathrm{p}}$ values obtained from the EXPLO5 V6.02 database and Ref. [13]; ${ }^{\mathrm{q}}$ values obtained from Refs. [14] and [18]; ${ }^{\mathrm{r}}$ values determined 2003 by Fraunhofer-Institut für Chemische Technologie, Pfinztal, Germany. 
A comparison of the values of $\Delta_{\mathrm{E}} U^{\circ}$ (an indication of the work performed by the explosive) of GNAP and of the reference systems GAP and polyGLYN demonstrates that GNAP possesses an approximately 10\% higher energy of explosion (GNAP: $-4813 \mathrm{~kJ} \cdot \mathrm{kg}^{-1}$, GAP: $-4307 \mathrm{~kJ} \cdot \mathrm{kg}^{-1}$, polyGLYN: $\left.-4433 \mathrm{~kJ} \cdot \mathrm{kg}^{-1}\right)$. Other important values for the evaluation of the energetic performance are the detonation velocity $V_{\text {Det }}$ and the detonation pressure $p_{\mathrm{CJ}}$. In case of $V_{\text {Det, }}$, the value of GNAP $\left(7165 \mathrm{~m}^{\cdot} \mathrm{s}^{-1}\right)$ exceeds the values of GAP and polyGLYN by $500 \mathrm{~m} \cdot \mathrm{s}^{-1}$ and $700 \mathrm{~m} \cdot \mathrm{s}^{-1}$, respectively. A comparison of the detonation pressures shows that $p_{\mathrm{CJ}}$ of GNAP $(176 \mathrm{kbar})$ is higher by about $50 \mathrm{kbar}$, in the case of GAP and $30 \mathrm{kbar}$, in the case of polyGLYN. Regarding the specific impulse $I_{\mathrm{s}}$, all of the three glycidyl polymers gave values within a narrow range (205-209 s).

In summary, the calculated results of the energetic data, show GNAP to be better in terms of $\Delta_{\mathrm{E}} U^{\circ}, V_{\text {Det }}$ and $p_{\mathrm{CJ}}$ compared to GAP and polyGLYN, which establishes GNAP as an interesting substance for further investigations concerning its suitability as a binder in energetic formulations.

\section{Conclusion}

A new glycidyl-based energetic polymer was synthesized, with GAP as the starting material. The desired compound glycidyl nitramine polymer (GNAP) was obtained in a four step synthesis as a sticky yellow powder. The successful synthesis of the compounds was proven by infrared spectroscopy and elemental analysis. The thermal and physical stabilities of GNAP were determined by DSC measurements and BAM drop hammer and friction tester, respectively. It turned out, that GNAP is insensitive towards friction and equal to or less sensitive towards impact than the commercially available energetic polymers GAP and polyGLYN.

The energetic data of GNAP were calculated using the values of the bomb calorimetric measurements and the EXPLO5 version 6.02 computer program. The values obtained revealed a higher energy of explosion, detonation velocity and pressure for GNAP than the values of the comparable compounds GAP and polyGLYN.

Due to its solid character, no or at least less curing agents would be needed when used as a binder. GNAP is therefore of interest as a potential new energetic binder in energetic formulations. 


\section{Acknowledgments}

Financial support of this work by the Ludwig-Maximilian University of Munich (LMU), the U.S. Army Research Laboratory (ARL), the Armament Research, Development and Engineering Center (ARDEC) the Office of Naval Research (ONR) under grant no. ONR.N00014-12-1-0538, and the Bundeswehr Wehrtechnische Dienststelle für Waffen und Munition (WTD 91) under grant no. E/E91S/FC015/CF049 is gratefully acknowledged. The authors acknowledge collaborations with Dr. Mila Krupka (OZM Research, Czech Republic) in the development of new testing and evaluation methods for energetic materials and with Dr. Muhamed Sućeska (Brodarski Institute, Croatia) in the development of new computational codes to predict the detonation and propulsion parameters of novel explosives. We are indebted to and thank Drs. Betsy M. Rice, Jesse Sabatini and Brad Forch (ARL, Aberdeen, Proving Ground, MD) for many inspired discussions. Stefan Huber is thanked for assistance with sensitivity and bomb calorimetric measurements. Katrin Horky and Christine Pösl (AK Schnick) are thanked for their help regarding TGA measurements.

\section{References}

[1] Ang H.G., Pisharath S., Energetic Polymers - Binders and Plasticisers for Enhancing Performance, Wiley-VCH Verlag, Weinheim, 2012, pp. 1-7; ISBN 978-3-527-33155-0.

[2] Agrawal J.P., High Energetic Materials: Propellants, Explosives and Pyrotechnics, Wiley-VCH Verlag, Weinheim, 2009, p. 229; ISBN 978-3-527-32610-5.

[3] a) Cossu C., Heuzey M.-C., Lussier L.-S., Dubois C., Early Development of a Biodegradable Energetic Elastomer, J. Appl. Polym. Sci., 2011, 119(6), 3645-3657;

b) Betzler F.M., Klapötke T.M., Sproll S.M., Synthesis of Glycidyl-5(carboxyethyl-1H-tetrazole)polymer and 1,2-Bis(5-carboxyethyl-1H-tetrazolyl) ethane as Polymeric Precursor, Eur. J. Org. Chem., 2013, 2013(3), 509-514; c) Klapötke T.M., Sproll S.M., Investigation of Nitrogen-rich Energetic Polymers Based on Alkylbridged Bis-(1-methyl-tetrazolylhydrazines), J. Polym. Sci. Pol. Chem., 2010, 48(1), 122-127; d) Bellamy A.J., King D.S., Golding P., Synthesis of Energetic Polymers by the Introduction of Energetic Groups onto Polymeric Primary and Secondary Amines, Propellants Explos. Pyrotech., 2004, 29(3, 509-514; e) Provatas A., Energetic Polymers and Plasticisers for Explosive Formulations - A Review of Recent Advances, Report DSTO-TR-966, 2000.

[4] Blomquist H.R., Gas generating material for vehicle occupant protection device, US Patent 6802533, 2004.

[5] NATO Standardization Agreement (STANAG) on Explosives, Impact Sensitivity Tests, No. 4489, $1^{\text {st }}$ ed., Brussels, 1999. 
[6] NATO Standardization Agreement (STANAG) on Explosives, Friction Sensitivity Tests, No. 4487, $1^{\text {st }}$ ed., Brussels, 2002.

[7] a) WIWEB-Standardarbeitsanweisung 4-5.1.02, Ermittlung der Explosionsgefährlichkeit, hier der Schlagempfindlichkeit mit dem Fallhammer, Erding, 2002; b) WIWEB-Standardarbeitsanweisung 4-5.1.03, Ermittlung der Explosionsgefährlichkeit oder der Reibeempfindlichkeit mit dem Reibeapparat, Erding, 2002.

[8] http://www.bam.de (accessed 02.07.2015)

[9] http://www.ozm.cz/en/sensitivity-tests/esd-2008a-small-scale-electrostatic-sparksensiti- vity-test/ (accessed 02.07.2015)

[10] Staudinger H., Meyer J., New Organic Compounds of Phosphorous. III. Phosphinemethylene Derivatives and Phosphinimines, Helv. Chim. Acta, 1919, 2, 635-646.

[11] Hesse M., Meier H., Zeeh B., Spektroskopische Methoden in der Organischen Chemie, $7^{\text {th }}$ ed., Thieme Verlag, Stuttgart, 2005, pp. 33-67; ISBN 978-3-13576107-7.

[12] Siguenza C., Galera P., Otero-Aenlle E., Vibrational Study of some Alkylamine Hydrochlorides, Spectrochim. Acta, 1980, 37(6), 459-460.

[13] Meyer R., Köhler J., Homburg A., Explosives, $6^{\text {th }}$ ed., Wiley-VCH Verlag, Weinheim, 2007, p. 151; ISBN 978-3-527-31656-4.

[14] Provatas A., Characterisation and Polymerisations Studies of Energetic Binders, Report DSTO-TR-1171, 2001.

[15] Klapötke T.M., Stein M., Stierstorfer J., Salts of $1 H$-Tetrazole - Synthesis, Characterization and Properties, Z. Anorg. Allg. Chem., 2008, 634(10), 1711-1723.

[16] a) Wiberg E., Wiberg N., Lehrbuch der Anorganischen Chemie, 101. ed., de Gruyter Verlag, Berlin, New York, 1995; ISBN 3-11-012641-9; b) http://webbook.nist.gov/ chemistry (accessed 02.07.2015).

[17] a) Sućeska M., Calculation of the Detonation Properties of C-H-N-O Explosives, Propellants Explos. Pyrotech., 1991, 16(4), 197-202; b) Sućeska M., EXPLO5 V.6.02.; Zagreb (Croatia), 2013.

[18] Diaz E., Heats of Combustion and Formation of New Energetic Thermoplastic Elastomers Based on GAP, PolyNIMMO and PolyGLYN, Propellants Explos. Pyrotech., 2003, 28(3), 101-106. 